\title{
Latent inhibition: No effect of intertrial interval of the preexposure trials
}

\author{
TERRY L. DEVIETTI and OWEN V. BARRETT \\ Central Washington University, Ellensburg, Washington
}

\begin{abstract}
Three experiments are reported in which the intertrial interval (ITI) of six preexposure (PE) trials was varied in a latent inhibition (LI) paradigm using rats and a one-trial fear conditioning task. No effect of the ITI was obtained in any experiment. However, at all ITIs tested, LI was obtained when the to-be-conditioned stimulus and the conditioned stimulus were of long duration $(15 \mathrm{sec})$, and LI was not obtained when such stimuli were of short duration $(3 \mathrm{sec})$. These results are interpreted in terms of a new hypothesis of latent inhibition.
\end{abstract}

Nonreinforced presentations of a stimulus retard conditioning performance when that stimulus is subsequently paired with an unconditioned stimulus (US). This phenomenon, termed latent inhibition (LI; Lubow \& Moore, 1959), has been demonstrated in a variety of species and tasks, and seldom occurs if fewer than 18 preexposure (PE) trials to the to-be-conditioned stimulus are administered (see Lubow, 1973, for a review). However, we have consistently obtained LI with six PE trials in a one-trial fear conditioning task (DeVietti, Emmerson, \& Wittman, 1982; DeVietti, Wittman, \& Comfort, 1980; DeVietti, Wittman, Emmerson, \& Thacher, 1981). We are currently investigating the factor(s) responsible for our finding of the rapid development of LI. In our previous studies, we initiated a 15 -sec tone at 2 and $7 \mathrm{~min}$ of a 10 -min session on each of 3 successive days for a total of six PE trials. Previous literature indicates that LI varies directly with the intertrial interval (ITI) of the PE trials when such trials are administered in a single session (Lantz, 1973; Schnur \& Lubow, 1976). Schnur and Lubow (1976) found that PE trials with an ITI of $70 \mathrm{sec}$ produced greater LI than PE trials with an ITI of $10 \mathrm{sec}$. Lantz (1973) used ITIs of $2,10,30$, and $150 \mathrm{sec}$ in the PE trials and, although such trials were confounded with apparatus preexposure duration, showed that, starting with the 10 -sec ITI, LI increased as the ITI increased. By these standards, the ITI in our procedure is exceedingly long, and thus may account for our finding of LI with six PE trials.

The following experiments were designed to evaluate this possibility.

\section{EXPERIMENT 1}

In Experiment 1, we administered a total of six PE trials to a 15 -sec tone, two PE trials during a 10-min session on each of 3 days. The ITI of the presentations on each

Supported in part by the small grants program of Central Washington University. Please address reprint requests to: Terry L. DeVietti, Department of Psychology, Central Washington University, Ellensburg, WA 98926 . day was varied in different groups between 10 and $300 \mathrm{sec}$.

\section{Method}

Subjects and Apparatus. The animals were 36 male Long-Evans rats from the Central Washington University psychology department animal colony and were 90-120 days of age at the beginning of the experiment. The apparatus has been described in detail elsewhere (DeVietti \& Larson, 1971). Briefly, two identical chambers with grid floors were used for PE treatments, fear conditioning, and testing. A small hole just off center in the front wall of each chamber allowed the insertion of a drinking tube. A drinkometer circuit was formed between the water in the drinking tube and the grid floor. A $10-\mathrm{cm}$ loudspeaker for delivery of the to-be-conditioned and conditioned stimulus, a $1200-\mathrm{Hz}, 90-\mathrm{dB}(\mathrm{A})$, re $.00002 \mathrm{~N} / \mathrm{m}^{2}$ SPL tone of $15 \mathrm{sec}$ was positioned at floor level behind the rear wall of each chamber. Scrambled footshock, delivered through the grid floors of the chambers, was $1.6 \mathrm{~mA}, 3 \mathrm{sec}, 60 \mathrm{~Hz}$. The chambers were individually enclosed in lighted, fan-ventilated, soundattenuated boxes. A $25-\mathrm{W}$ bulb attached to the ceiling of the boxes provided illumination.

Procedure. The animals were randomly assigned to groups and individually housed and maintained ad lib on food and water. They were handled, once a day for 2 days and then placed, individually, into one of the two chambers for $10 \mathrm{~min}$ on each of 3 successive days. Thirtyone animals were given two PE trials to the 15-sec tone on each of these 3 days. Depending on the group assignment, the ITI of these PE trials was $10,30,60,120,180$, or $300 \mathrm{sec}$ (offset to onset). The onset of the first PE tone of any 1 day was determined randomly, with the restrictions that it would not occur before Min 1 of the session, and that the last PE tone, determined by the ITI, would occur before Min 9 of the session. The 5 remaining animals did not receive PE trials of any ITI and simply were placed in the apparatus for $10 \mathrm{~min}$ on each of 3 consecutive days. During the last 10 -min session, the water bottles were removed from the home cages and the animals, 24-h deprived, were allowed to complete 110 licks from the drinking tube that was present in the chamber the following day. Water was available in the apparatus only on this day and the test day (see below).

The next day, each animal was fear conditioned by pairing the 15sec tone with the 3 -sec footshock. The shock onset coincided with the tone offset. The tone was initiated 2 min after the animal's placement in the chamber, and the animal was removed to the home cage $45 \mathrm{sec}$ after the termination of the footshock. The following day, the water was again removed from the home cages and the animals were tested $24 \mathrm{~h}$ later. At that time, each rat was placed in the chamber and, after 100 licks on the drinking tube had been completed, the tone was automatically presented and remained on until the animal licked an additional 10 times. The latencies to complete 10 licks in the presence of the tone served as our measure of conditioning strength. No cut-off criterion was imposed on the test. 


\section{Results and Discussion}

The drink latencies in the presence of the tone in the test are shown in the top of Table 1. A weighted means one-way analysis of variance showed a reliable effect of groups $[F(6,29)=4.57, p<.01]$, and planned comparisons with the $t$ test showed that each of the PE groups had shorter drink latencies in the test than did the NPE group ( $p$ s $<.05$ ). Thus, LI was obtained with six PE trials, and this effect was independent of the ITI of the PE trials.

\section{EXPERIMENT 2}

Experiment 1 showed no effect of the ITI in the PE trials. However, as the six PE trials were administered across 3 successive days, two 24-h intervals intervened between PE trials. To evaluate the effect of these intervals, we gave the six PE trials in one session and varied the ITI of the trials.

\section{Method}

Twenty-eight rats of the same sex, age, and stock described previously were randomly assigned in equal numbers to each of four groups. The procedure was identical to that of Experiment 1, except that following the two successive 10-min sessions, during which, in this experiment, no PE trials were given, the third session was expanded to $30 \mathrm{~min}$ and animals in the four groups were given either zero or six PE trials to the 15 -sec tone. In the PE groups, the ITI was 10,150 , or $300 \mathrm{sec}$ (offset to onset).

\section{Results and Discussion}

The drink latencies in the presence of the tone in the test are shown in the middle of Table 1. A one-way analysis of variance indicated a reliable effect of groups $[F(3,24)=3.51, p<.05]$, and planned comparisons with the $t$ test showed that each of the PE groups had shorter drink latencies than did the NPE group

Table 1

Latencies (in Seconds) to Drink in the Presence of the Test Tone as a Function of Intertrial Interval of the Preexposure Trials

\begin{tabular}{lrrr}
\hline \multicolumn{1}{c}{ Group } & N & Mean & Standard Error \\
\hline & & Experiment 1 & \\
NPE & 5 & 702.80 & 151.40 \\
PE-10 sec & 5 & 61.40 & 31.33 \\
PE-30 sec & 5 & 176.60 & 88.38 \\
PE-60 sec & 6 & 200.17 & 96.30 \\
PE-120 sec & 5 & 197.40 & 108.96 \\
PE-180 sec & 5 & 210.40 & 68.44 \\
PE-300 sec & 5 & 215.80 & 71.30 \\
& & & \\
NPE & 7 & 697.00 & 120.50 \\
PE-10 sec & 7 & 359.86 & 76.08 \\
PE-150 sec & 7 & 402.00 & 136.37 \\
PE-300 sec & 7 & 256.14 & 42.96 \\
& & & \\
NPE & 7 & 641.00 & 149.32 \\
PE-10 sec & 7 & 323.29 & 77.74 \\
PE-150 sec & 7 & 530.86 & 112.63 \\
PE-300 sec & 7 & 539.14 & 111.70 \\
\hline
\end{tabular}

Note-Experiments 1 and 2 used a 15-sec-duration stimulus and Experiment 3 used a 3 -sec-duration stimulus.
( $p$ s $<.05)$. Thus, LI was obtained with six PE trials given in a single session, and the ITI of such trials was without effect.

\section{EXPERIMENT 3}

Experiments 1 and 2 showed that, with six PE trials to a 15-sec tone, LI was obtained with ITIs ranging from 10 through $300 \mathrm{sec}$. Furthermore, this result occurred both when the PE trials were administered two per day for 3 days or when all six PE trials were administered in a single session. We have previously demonstrated that $\mathrm{LI}$ is not obtained with six PE trials to a 3-sec tone (DeVietti et al., 1986) when such trials were administered two per day for 3 days either with an ITI of $300 \mathrm{sec}(\mathrm{Ex}-$ periment 1) or an ITI of $30 \mathrm{sec}$ (Experiment 2). In Experiment 3, we used six PE trials with a 3-sec tone and varied the ITI between 10 and $300 \mathrm{sec}$ in a single session.

\section{Method}

The animals were 28 rats of the same sex, stock, and age described previously. The procedure was identical to that of Experiment 2 with the single exception that a 3-sec tone, rather than a 15-sec tone, was used in the PE trials and as the conditioned stimulus (CS) in the fear conditioning trial.

\section{Results}

The latencies to drink in the presence of the tone in the test are shown in the bottom of Table 1. A one-way analysis of variance failed to differentiate the performance of the four groups $[F(3,24)=1.33, p>.05]$. Thus, LI was not obtained at any ITI with six PE trials, administered in a single session, with a $3-\mathrm{sec}$ tone.

\section{GENERAL DISCUSSION}

The results of the present experiments, in combination with some previous work (DeVietti et al., 1986), can be readily summarized. Given six PE trials, ITIs ranging from "short" (10-30 sec) through "long" $(300 \mathrm{sec})$ were without effect in producing LI. Also, the pattern of administration of the six PE trials was without effect; that is, PE trials given two per day for 3 days or six PE trials given in a single session produced the same results.

However, the duration of the to-be-conditioned and conditioned stimulus had a profound effect on the finding of LI. LI was obtained at every ITI, both at two PE per day for 3 days and at six PE trials in one session when the duration of the to-be-conditioned and conditioned stimulus was $15 \mathrm{sec}$. In contrast, LI was not obtained with similar manipulations when the duration of the to-be-conditioned and conditioned stimulus was $3 \mathrm{sec}$. DeVietti et al. (1986) proposed a new hypothesis, the trace hypothesis, to account for these facts. The trace hypothesis holds that the salience of a stimulus is not necessarily invariant throughout its duration. It is assumed that the associability of a stimulus is directly related to its salience at the moment of US presentation. With regard to the LI phenomenon, the trace hypothesis holds that, as a consequence of the PE trials, only the onset and initial segments of the CS are salient (i.e., capable of supporting conditioning). Following this initial salient period, the CS loses salience and, thus, a US presented during these segments of the CS is ineffective in supporting conditioning. In short, we argue that $\mathrm{LI}$ is effectively a trace conditioning phenomenon. When viewed in this manner, a "long" stimulus should be more effective than a "short" stimulus in producing LI because, in the conditioning trial, the effective trace interval (CS loss of salience to the onset of the US) is longer in the former than in the latter case. 
We conclude that our finding of the rapid development of LI (DeVietti et al., 1980; DeVietti et al., 1981; DeVietti et al., 1982; DeVietti et al., 1986) resulted primarily, if not exclusively, from the use of a long (15sec) stimulus. This conclusion appears warranted, as the present experiments clearly showed that the ITI of the PE trials was without effect.

\section{REFERENCES}

DeVietti, T. L., Bauste, R. L., Nutt, G., Barrett, O. V., Daly, K., \& Petree, A. D. (1986). Latent inhibition: A trace conditioning phenomenon? Manuscript submitted for publication.

DeVietti, T. L., Emmerson, R. Y., \& Wittman, T. K. (1982). Disruption of latent inhibition by placement of an electrode in the dorsal hippocampus. Physiological Psychology, 10, 46-50.

DeVIETTI, T. L., \& LARSON, R. C. (1971). ECS effects: Evidence supporting state dependent learning in rats. Journal of Comparative \& Physiological Psychology, 74, 407-415.

DeVietti, T. L., Wittman, T. K., \& Comfort, M. K. (1980). Rapid development of latent inhibition: No effect of implanted site. Psychological Reports, 45, 473-474.

DeVietti, T. L., Wittman, T. K., Emmerson, R. Y., \& Thacher, D. O. (1981). Either stimulation of the mesencephalic reticular formation or a flashing light increases latent inhibition to a toneconditioned stimulus. Behavioral \& Neural Biology, 32, 308-318.

LANTZ, A. E. (1973). Effect of number of trials, interstimulus interval, and dishabituation during CS habituation on subsequent conditioning in a CER paradigm. Animal Learning \& Behavior, 1, 273-277.

Lubow, R. E. (1973). Latent inhibition. Psychological Bulletin, 79, 398-407.

Lubow, R. E., \& Moore, A. U. (1959). Latent inhibition: The effect of nonreinforced pre-exposure to the conditioned stimulus. Journal of Comparative \& Physiological Psychology, 53, 415-419.

SCHNuR, P., \& LuBow, R. E. (1976). Latent inhibition: The effects of ITI and CS intensity during preexposure. Learning \& Motivation, 7, 540-550.

(Manuscript received for publication June 16, 1986.) 